\title{
Evolution of magnetic response as a function of annealing temperature in Fe-based alloys
}

\author{
Damián Gargicevich ${ }^{1}$, Federico Guillermo Bonifacich ${ }^{1}$, \\ Osvaldo Agustín Lambri ${ }^{1}$,Pablo Chiappero ${ }^{1}$, José Ángel Cano ${ }^{1}$, \\ Griselda Irene Zelada ${ }^{1}$, José Ignacio Pérez-Landazábal ${ }^{2,3}$, \\ Vicente Recarte ${ }^{2,3}$, Víctor Martín Galván Josa ${ }^{4}$, \\ María Cecilia Blanco ${ }^{5}$, Gabriel Julio Cuello ${ }^{6}$
}

\author{
${ }^{1}$ CONICET-UNR, Laboratorio de Materiales, Escuela de Ingeniería Eléctrica, Centro de Tecnología e Investigación \\ Eléctrica, Facultad de Ciencias Exactas, Ingeniería y Agrimensura, Av. Pellegrini 250, 2000, Rosario, Santa Fe, Argenti- \\ na. \\ e-mail: gargi@fceia.unr.edu.ar; bonifaci@fceia.unr.edu.ar; olambri@fceia.unr.edu.ar; pjchiappero@gmail.com; \\ jacano@fceia.unr.edu.ar; gizelada@fceia.unr.edu.ar; \\ ${ }^{2}$ Departamento de Física, Universidad Pública de Navarra, Pamplona, España. \\ ${ }^{3}$ Instituto de Materiales Avanzados (INAMAT), Universidad Pública de Navarra, Campus de Arrosadía s/n, 31006 \\ Pamplona, Navarra, España. \\ e-mail: ipzlanda@unavarra.es; recarte@unavarra.es \\ ${ }^{4}$ CONICET-UNC, Facultad de Matemática, Astronomía y Física, Universidad Nacional de Córdoba, Medina Allende, \\ Ciudad Universitaria, 5000, Córdoba, Córdoba, Argentina. \\ e-mail: galvan@famaf.unc.edu.ar \\ ${ }^{5}$ CONICET-UNC, Facultad de Ciencias Químicas, Universidad Nacional de Córdoba, Av. Haya de la Torre, Ciudad \\ Universitaria, 5000, Córdoba, Córdoba, Argentina. \\ e-mail: ceciliablanco3@gmail.com \\ ${ }^{6}$ Instituto Laue-Langevin, 71, Av. des Martyrs, 38042, Grenoble, Isère, France. \\ e-mail: cuello@ill.eu
}

\section{ABSTRACT}

The magnetic response, coercive force and magnetic induction, in Fe-10at.\% Si, Fe-6at.\% Al-9at.\% Si and $\mathrm{Fe}-4$ at.\% Al-8at.\% Ge alloys as a function of the annealing temperature was determined and correlated to the microstructural state. The microstructural characterization was made through differential thermal analysis, mechanical spectroscopy and neutron thermodiffraction studies. It has been determined that the increase in the order degree and the decrease in the mobility of structural defects lead to a deterioration of the magnetic quality of the alloys above detailed.

Keywords: Fe-based alloys, microstructure, Improvement of magnetic properties, Hysteresis loops

\section{INTRODUCTION}

Fe-based alloys are often used as magnetic cores, which has a particular importance in energy conversion and transport, high frequency applications, magnetic recording, choke, inductors, etc. [1-4]. The study of the magnetic properties and its optimization plays a crucial role in the electric industry. In fact, it is know that order and recovery has a strong influence on the magnetic properties [1-3]. However, despite the spread technological use of magnetic alloys there is scarce bibliography about the relation between microstructure and magnetic behaviour.

In the present work, differential thermal analysis, mechanical spectroscopy and neutron thermodiffraction studies were performed to reveal the state of the microstructure. These studies were related to the characteristic parameters for describing the hysteresis loops; as coercive force and maximum induction reached at a given fixed field. The magnetic quality of the material is explained on the basis of the mobility of the domain walls controlled by the interaction with defects. Indeed, the great importance of the first part of the magnetization process before reaching the saturation elbow, which is utilized as working point in electrical machines, is well known [3,4]. Therefore, the study of the mobility of the domain walls controlled 
by the microstructure arises as a critical technological issue [3,4].

\section{MATERIALS AND METHODS}

Studied samples were polycrystals both commercial and laboratory prepared, of compositions: Fe-10at.\% Si Fe-6at.\% Al-9at.\% Si and Fe-4at.\% Al-8at.\% Ge. Fe-10at.\% Si were commercial samples provided by NKK Corp. Samples were homogenized at $1323 \mathrm{~K}$ during 1 hour under high vacuum and quenched in room temperature (RT) water.

Microstructure was analyzed by means of differential thermal analysis (DTA), mechanical spectroscopy (MS) and Neutron thermodiffraction (ND) studies.

DTA measurements were performed in a conventional differential calorimeter assembled at the Laboratory with stainless steel crucibles under pure Argon atmosphere at normal pressure. The heating rate was $5 \%$ minute and it was controlled by a Lake Shore DRC-91C device.

Mechanical spectroscopy measurements were performed in an inverted torsion pendulum at frequencies close to $1 \mathrm{~Hz}$ in free decaying vibrations [5]. Measurements have been performed under vacuum (about $10^{-5} \mathrm{~Pa}$ ). The employed samples were bars of rectangular section $(1 \mathrm{~mm} \times 2.2 \mathrm{~mm} \times 20 \mathrm{~mm})$. The maximum strain on the surface of the sample was $5 \times 10^{-5}$. Damping $\left(\mathrm{Q}^{-1}\right)$ and square frequency (which is proportional to the shear modulus), were measured with an error less than $2 \%$. The measurements were carried out during subsequent heating and cooling runs on the same specimen. A heating and its cooling run is hereafter called a thermal cycle. The heating rate was $1.5 \mathrm{~K} / \mathrm{min}$.

Neutron powder diffraction studies were performed at D20 and D1B installations in the Institute LaueLangevin (ILL), Grenoble, France. In situ experiments at D20 were performed during heating from RT up to $1050 \mathrm{~K}$ and from RT up to $1300 \mathrm{~K}$, for Iron Silicon and Fe-Al-Ge alloys, respectively. Measurements were performed under high vacuum $\left(10^{-2} \mathrm{~Pa}\right)$. The neutron wavelength was $\lambda=1.3 \AA$. The heating rate was $4 \mathrm{~K} / \mathrm{min}$. In addition, neutron thermodiffraction studies for Fe-Al-Si were performed at D1B. The used neutron wavelength was $\lambda=1.28 \AA$. Spectra were obtained under high vacuum $\left(10^{-2} \mathrm{~Pa}\right)$ from RT up to $1173 \mathrm{~K}$. The heating rate was $3 \mathrm{~K} / \mathrm{min}$.

Magnetic cycles were recorded at RT in a Laboratory assembled automatic loop tracer. Magnetic field was generated by a 3000 winding coil connected to an analogical wave generator Protek B-801 and a digital oscilloscope Rigol DS1052E used for data acquisition. The average of 5 cycles was considered for each measurement. Samples for magnetic loops were thermally treated step by step by increasing the temperature in $50 \mathrm{~K}$, starting from RT up to $1123 \mathrm{~K}$, under high vacuum. The heating rate was of $1.5 \mathrm{~K} / \mathrm{min}$ and the cooling was without furnace under high vacuum.

\section{RESULTS AND DISCUSSION}

\subsection{Differential thermal analysis}

Figure 1 shows the DTA thermogram measured in an as-quenched Fe-10at.\% Si sample (blue circles), from where three exothermic reactions at around $560 \mathrm{~K}, 640 \mathrm{~K}$ and $800 \mathrm{~K}$ can be observed. In addition, the change in base line related to the Curie temperature can be also observed to appear at around $973 \mathrm{~K}$. The first exothermic reaction at around $550 \mathrm{~K}$ was already related to increase in the degree of $\mathrm{B} 2$ order reached by the quenching process [6].

In addition, the exothermic peaks at around $640 \mathrm{~K}$ and $800 \mathrm{~K}$ were already related to the recovery of vacancies and the recovery of the structure, respectively. In fact, at around $600 \mathrm{~K}$ in high purity iron the total recovery of the excess of vacancies out of the equilibrium has been determined from positron annihilation spectroscopy [7-9]. Besides, a temperature of $800 \mathrm{~K}$ is in agreement with the temperature of recovery and recrystallization for iron $[10,11]$.

The thermogram for an as-quenched Fe-6at.\% Al-9at.\% Si sample (red squares) is also shown in Figure 1. It can be observed a clear exothermic reaction at around $650 \mathrm{~K}$ and subsequently at higher temperatures the change in baseline related to the Curie temperature at around $980 \mathrm{~K}$ appears. At the same temperature the $\mathrm{D}_{3} \rightarrow$ bcc transition develops, according to phase diagram [12,13].

The thermal reaction at lower temperature can be related to both the increase of the $\mathrm{D}_{3}$ order after the quenching process, in agreement with previous works [14], and to the recovery of vacancies [7-9]. In fact, the reaction peak is wide enough for involving a superposition of reaction processes.

The thermal behaviour for Fe-4at.\% Al-8at.\% Ge is shown in Figure 1 by means of green triangles. It 
can be seen a wide exothermic peak (two stage peak) between around $500 \mathrm{~K}$ and $673 \mathrm{~K}$ which can be related to the recovery of quenched-in-vacancies, in agreement with the Fe-10at.\% Si and Fe-6at.\% Al-9at.\% Si alloys and previous works [7-9]. The peak at higher temperatures of around $850 \mathrm{~K}$, which can be observed partially from $700 \mathrm{~K}$ onwards, can be related to the recovery and recrystallization of the structure [10,11].

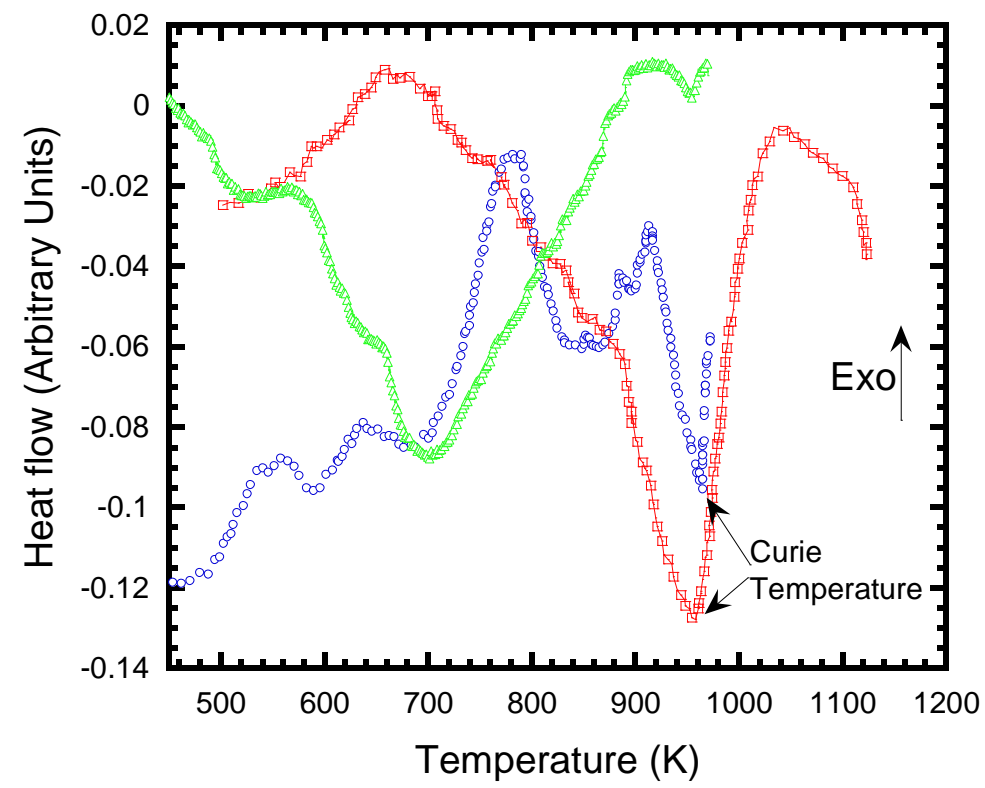

Figure 1: DTA thermograms for Fe-10at\% Si (blue circles), Fe-6at.\% Al-9at.\% Si (red squares), Fe-4at.\% Al-8at.\% Ge (green triangles). Not all measured points are shown for clarity.

\subsection{Neutron thermodiffraction}

Neutron thermodiffraction studies performed in the Fe-10at.\% Si samples, determined that the as-quenched sample has an ordered B2 structure and during its warming the alloy exhibits the B2 $\rightarrow$ bcc transformation at $973 \mathrm{~K}$; according to the phase diagram [6], see Figure 2. In addition, during the cooling the B2 order restores at the same temperature. Moreover, the order degree after a warming to $1050 \mathrm{~K}$ has increased, Figure 2

[6]. $\mathrm{DO}_{3}$ structure has never been observed from neutron patterns [6].

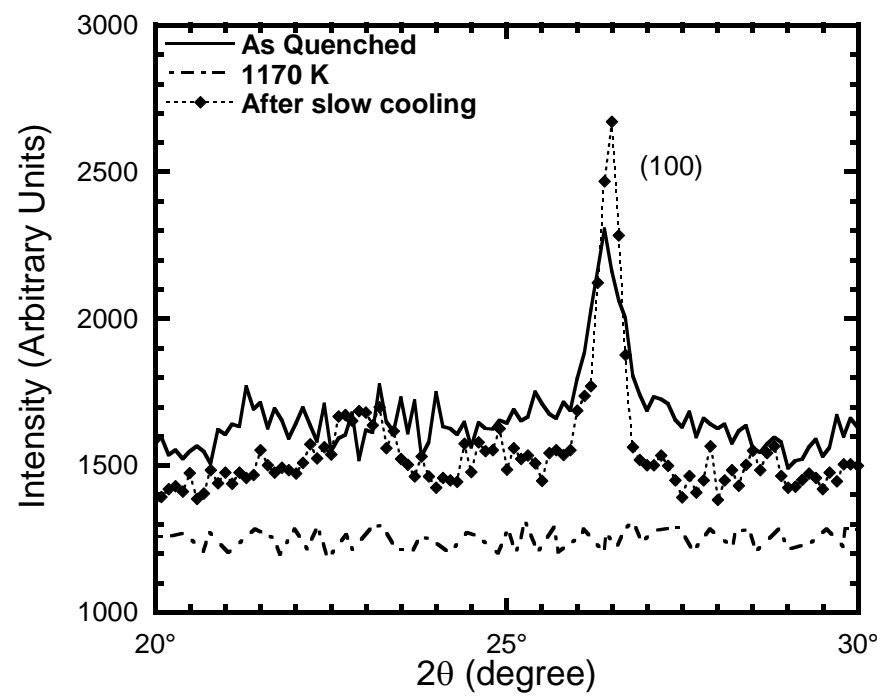

Figure 2: Neutron diffraction patterns for three different temperatures for Fe-10at.\% Si.

Neutron thermodiffraction studies in as-quenched Fe-6at.\% Al-9at.\% Si sample, determined the appearance of $\mathrm{DO}_{3}$ order at room temperature. Above $983 \mathrm{~K}$, the order disappears, as shown by the disappearance of the (lllll) and ( $\left.\begin{array}{lll}2 & 0 & 0\end{array}\right)$ reflections related to the $\mathrm{D}_{3}$ structure, Figure 3 [12,15]. In addition, 
during the cooling, after a previous heating up to $1150 \mathrm{~K}$, the order is restored approximately at the same temperature (983 K) [12].

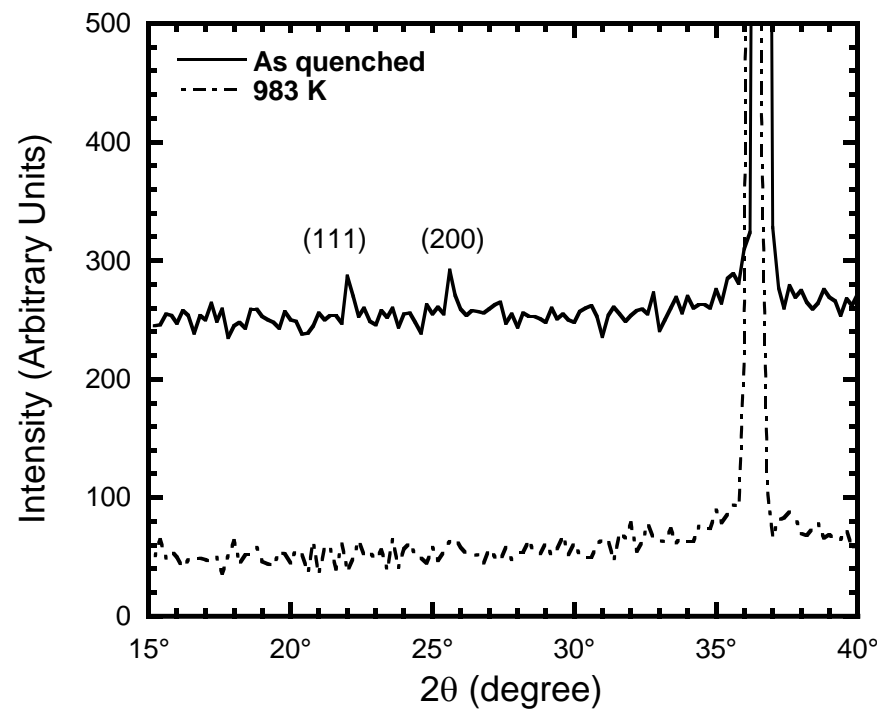

Figure 3: Neutron diffraction patterns for Fe-6at.\% Al-9at.\% Si at different temperatures.

Neutron thermodiffraction studies for Fe-4at.\% Al-8at.\% Ge have shown that this alloy is disordered in $\alpha$ phase in the whole explored temperature range, between room temperature and $1300 \mathrm{~K}$, see Figure 4.

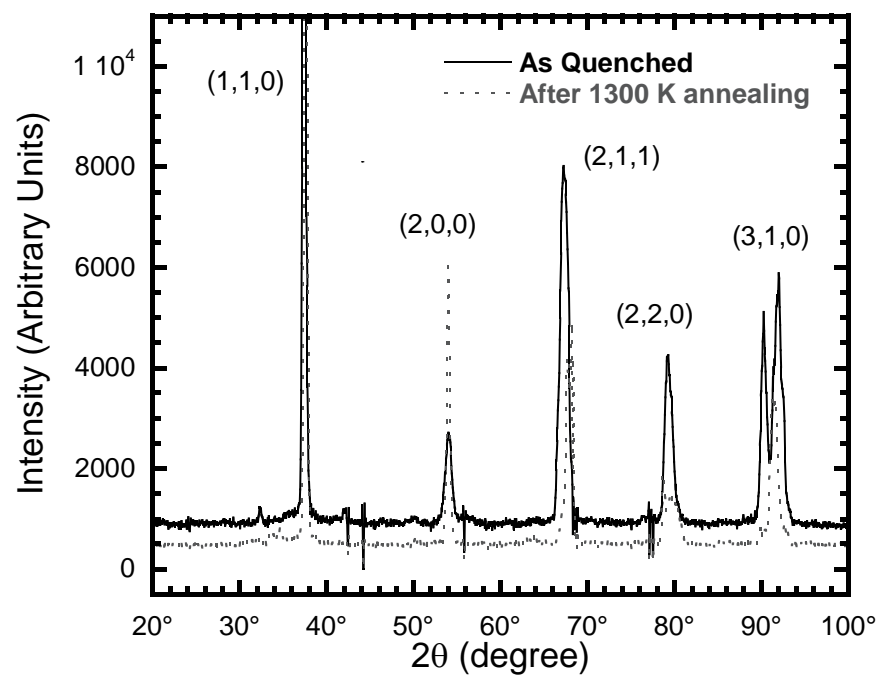

Figure 4: Neutron thermodiffraction pattern for Fe-4at.\% Al-8at.\% Ge.

\subsection{Mechanical spectroscopy}

In order to determine the effects of the microstructural changes above described on the mechanical behaviour, mechanical spectroscopy studies were performed. Figure 5 show the damping and modulus behaviour measured during warming as a function of temperature during successive thermal cycles performed up to different maximum temperatures for Fe-10at.\% $\mathrm{Si}$. All spectra show the characteristic grain boundary relaxation peak (GB), around $800 \mathrm{~K}[6,16]$. The peak temperature of the maximum related to GB moves towards higher temperatures during the cycles up to $973 \mathrm{~K}$. In the second heating the shift is very small, being larger during the third run up in temperature. In contrast, when the sample was previously measured up to $1050 \mathrm{~K}$, the peak temperature of the maximum during the heating run is shifted towards smaller temperatures (black diamond). Besides this, the peak temperature is very close to the initial peak 
temperature corresponding to the as-quenched sample. Nevertheless, the damping spectrum changes strongly when the sample was thermally treated up to $1273 \mathrm{~K}[6,17]$.

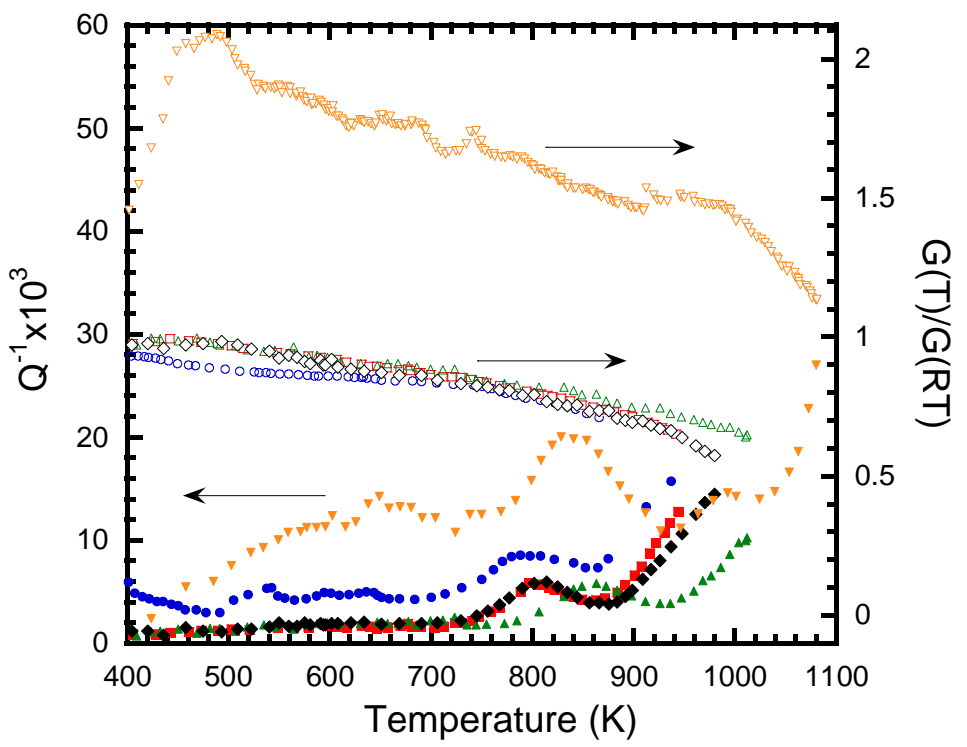

Figure 5: Damping $\left(\mathrm{Q}^{-1}\right)$, full symbols, and normalized shear modulus $(\mathrm{G}(\mathrm{T}) / \mathrm{G}(\mathrm{RT}))$, empty symbols, as a function of temperature for $\mathrm{Fe}-10 \mathrm{at} . \% \mathrm{Si}$ alloy. Blue circles, as-quenched sample; red squares, after heating to $973 \mathrm{~K}$; green triangles, after two heating to $973 \mathrm{~K}$; black diamonds, after heating to $1050 \mathrm{~K}$; orange inverted triangles, after a heating to $1273 \mathrm{~K}$. Only some measured points where plotted for clarity.

During the recovery of the structure above $800 \mathrm{~K}$, some dislocations move to the grain boundaries reducing their mobility, leading to the small increase of the $800 \mathrm{~K}$ peak temperature in the second warming run, red squares in Figure 5. In fact, the increase of the order degree after reaching $973 \mathrm{~K}$ produces an increase of internal stresses generated by the reorganization of defects in the ordered B2 phase. In particular dislocation must move in pairs towards the grain boundary where they are locked, reducing the grain boundary mobility [6]. In addition, the increase in the modulus values shown in Figure 5 for the second and subsequent warming runs is in agreement with the recovery process and with the assumption of an increase of internal stress developed by the dissociation of superdislocations in the B2 superlattice obtained during cooling.

During heating up to $1050 \mathrm{~K}$ the sample transforms according to the phase diagram. The B2 phase transforms to a bcc at $973 \mathrm{~K}$ and for higher temperatures the sample is disordered and the super dislocations disappear. Then, the structure can recover quenched-in-defects, which were retained in the ordered B2 superlattice. This effect leads to shift the peak temperature of GB towards smaller temperature. Besides, a thermal treatment at temperatures above $1273 \mathrm{~K}$ removes more quenched-in-dislocations associated to grain boundaries thus improving the mobility of grain boundaries and consequently increasing the GB peak height. The large modulus increases in the second heating run for the sample slow cooled from $1273 \mathrm{~K}$ agrees with a better reorganization of the dislocation structure.

The behaviour of the modulus as the function of temperature is shown through the behaviour of the ratio $\mathrm{G}(\mathrm{T}) / \mathrm{G}(\mathrm{RT})$, where $\mathrm{G}(\mathrm{RT})$ is the shear modulus at room temperature, as a function of temperature. The first increase in the modulus between $400 \mathrm{~K}$ and $500 \mathrm{~K}$ can be related to an interaction process between point defects and dislocations.

Figure 6 shows the damping spectra measured up to $1130 \mathrm{~K}$ (left axis) for a Fe-6at.\% Al-9at.\% Si sample for two subsequent thermal cycles. The damping change between $700 \mathrm{~K}$ and $1000 \mathrm{~K}$ is small $\left(\mathrm{Q}^{-1} \sim 2 \times 10^{-3}\right)$ but the damping increases strongly up to values $\mathrm{Q}^{-1}$ of about $110 \times 10^{-3}$ for higher temperatures. During the subsequent cooling run a damping peak develops. A thermal hysteresis in the damping of about $100 \mathrm{~K}$ appears in the temperature interval $850-1050 \mathrm{~K}$. Besides, the elastic modulus (ratio $\mathrm{G}(\mathrm{T}) / \mathrm{G}(\mathrm{RT})$ ) exhibited a hysteretic behaviour in the same temperature range, see right axis in Figure 6 . The modulus values during the cooling runs were smaller than during the heating runs.

As it was already pointed out in Ref. [12] the Fe-6at.\% Al-9at.\% Si sample is $\mathrm{D}_{3}$ ordered at room temperature, Figure 3. However, at temperatures close to $983 \mathrm{~K}$, the $\mathrm{D}_{3}$ structure changes to bcc in 
agreement with the ternary phase diagram [13]. This temperature is close to the one where the damping starts to increase strongly $(980 \mathrm{~K})$. Moreover, the temperature where the strong increase in the damping appears does not shift towards higher temperatures when the vibration frequency is increased. This kind of behaviour is the usual one for a phase transition process [19], in agreement with the neutron diffraction results and phase diagram. As in previous studied cases, after the $\mathrm{DO}_{3} \rightarrow$ bcc transition, the order degree is reduced and then the mobility of dislocations and grain boundaries is enhanced, leading to a recovery of the microstructure. Consequently, again the GB relaxation peak appears during the cooling process. The temperature of this peak is also close to the solute peak for iron $[6,11,12]$.

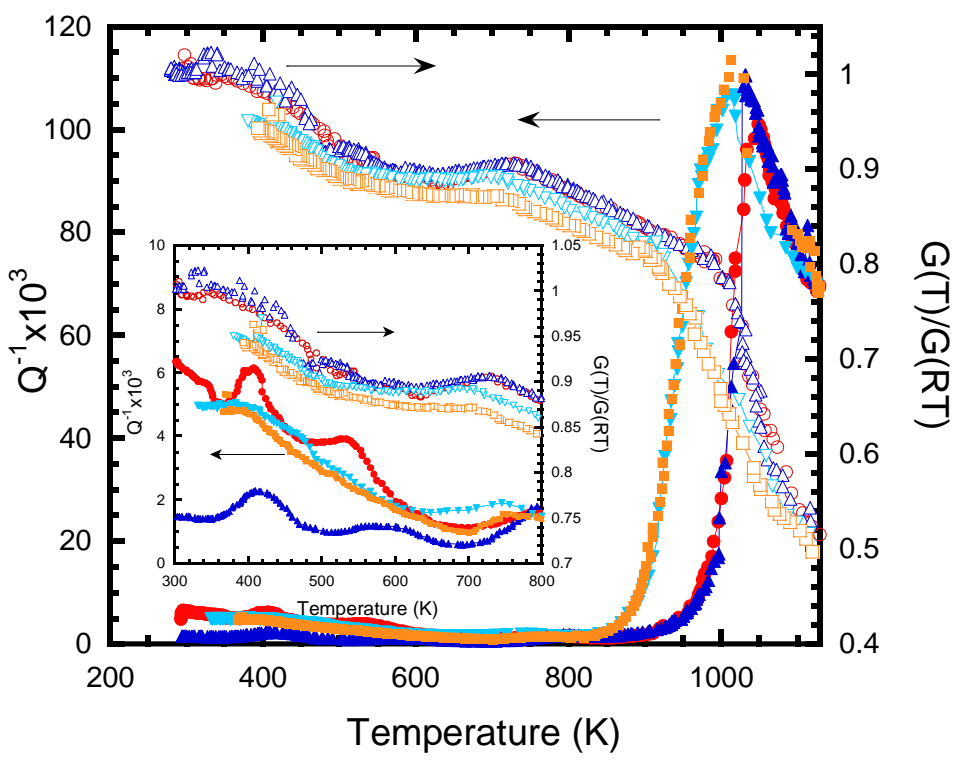

Figure 6: Damping $\left(\mathrm{Q}^{-1}\right)$, full symbols, and normalized shear modulus $(\mathrm{G}(\mathrm{T}) / \mathrm{G}(\mathrm{RT}))$, empty symbols, as a function of temperature. Blue triangles, heating first thermal cycle; inverted light blue triangles, cooling first thermal cycle; red circles, heating second thermal cycle; orange squares, cooling second thermal cycle. Inset shows a zoom of low temperature spectra.

Returning to the influence of the thermal cycles on the mechanical spectroscopy response, it can be seen that, the thermal cycles lead to an increase in the damping values in the temperature interval from room temperature up to around $700 \mathrm{~K}$, see Figure 6. It indicates that some recovery of the microstructure has taken place, due to the increase in the magneto-mechanical damping contribution.

Besides this, the damping and the modulus curves during the subsequent thermal cycles up to $1130 \mathrm{~K}$ are not modified. Moreover, by increasing the final temperature of the thermal cycles up to $1200 \mathrm{~K}$ does not modify the damping and modulus behaviours.

Figure 7 shows the behaviour of both the damping and modulus as a function of temperature for a $\mathrm{Fe}$ 4at.\% Al-8at.\% Ge alloy. As it can be seen from the Figure during the first run up in temperature the damping slightly decreases up to around $620 \mathrm{~K}$, followed by an increase in the damping values from $620 \mathrm{~K}$ onwards. Moreover, the GB peak can be observed at around $800 \mathrm{~K}$. In addition, the modulus exhibit firstly an increase from around $400 \mathrm{~K}$ up to around $600 \mathrm{~K}$, followed by a decrease as the temperature increases. The decrease in damping values and the increase in the modulus up to a temperature of around $600 \mathrm{~K}$ is similar to the exhibited by Fe-10at.\% Si and it can be related to the pinning of dislocations for point defects. However, the decrease in the damping values between $400 \mathrm{~K}$ and around $600 \mathrm{~K}$ can take a contribution from the magneto-mechanical contribution.

During the second warming in the second thermal cycle the damping values in the temperature range between $400 \mathrm{~K}$ and around $650 \mathrm{~K}$ increase, exhibiting the appearance of a damping peak at around $570 \mathrm{~K}$ which can be related to the interaction of defects with dislocations. Moreover, the height of the grain boundary peak has increased as a consequence of the recovery of the structure over $873 \mathrm{~K}$ (see Figure 1). The recovery of the microstructure remove quenched-in-defects and -dislocations located at the grain boundaries and then the mobility of GB is increase giving rise to the increase in the GB peak height. In addition, after the development of the recovery, the reorganization of the microstructure is revealed by the more monotonously 
decrease of the modulus values as the temperature is increased.

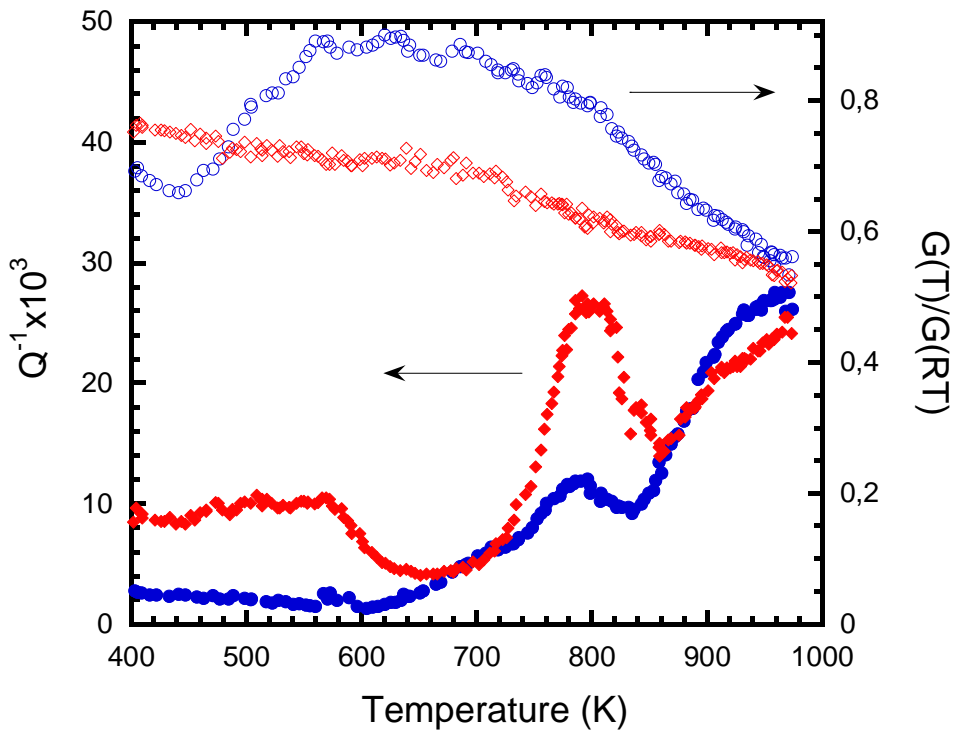

Figure 7: Damping $\left(\mathrm{Q}^{-1}\right)$, full symbols, and normalized shear modulus $(\mathrm{G}(\mathrm{T}) / \mathrm{G}(\mathrm{RT}))$, empty symbols, as a function of temperature for Fe-4at.\% Al-8at.\% Ge. Blue circles, heating first thermal cycle; red diamonds, heating second thermal cicle. Only half points are shown for clarity.

\subsection{Hysteresis loops}

Figure 8 shows the behaviour of the value of the magnetic induction at the tips, Bm, corresponding to $\mathrm{H}=150 \mathrm{~A} /$ winding and the coercive force, $\mathrm{Hc}$, as a function of the annealing temperature. As it can be seen from the Figure $\mathrm{Bm}$ and $\mathrm{Hc}$ do not exhibit a monotonous behaviour as a function of annealing time, allowing us to separate the curves in four zones as the temperature increases.

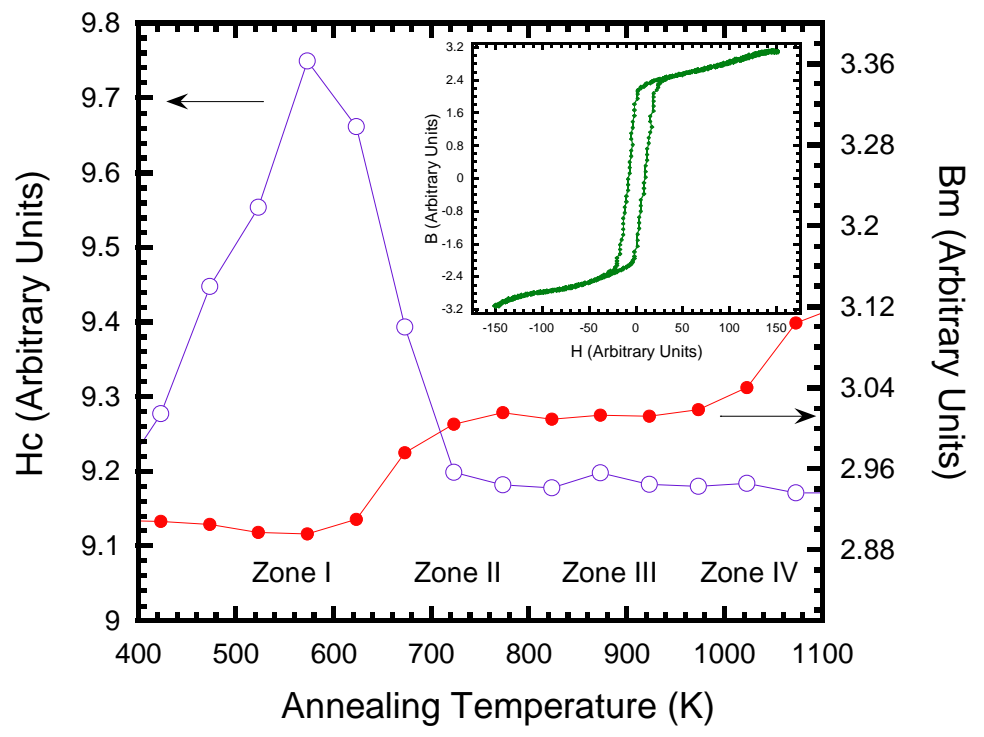

Figure 8: $\mathrm{Bm}$ and $\mathrm{Hc}$ as a function of annealing temperature for Fe-10at.\% Si. Magnetic loops were traced at RT. Inset shows a hysteresis loop.

Therefore, paying attention to the microstructural evolution above described, we can explain the behaviour of $\mathrm{Bm}$ and $\mathrm{Hc}$ in each one of the temperature intervals detailed in Figure 8. Indeed, the behaviour of $\mathrm{Bm}$ and $\mathrm{Hc}$ in zone I can be related to the increase of the order degree promoted by the temperature increases (see Figure 1) and also for the pinning of dislocations (see Figure 5). The increase of internal 
stresses leads to a decrease in the mobility of the domains walls thorough a magnetostrictive coupling, reducing $\mathrm{Bm}$ and increasing $\mathrm{Hc}$.

In zone II, the start of the GB movement is occurring, due to the start of the low temperature tail of GB peak, so dislocations at the grain boundaries and grain boundary increase their mobility, Figure 5; allowing a rearrangement of the microstructure. Then, the rearrangement of the microstructure, in order to decrease the free energy by heating, leads to a decrease in the amount of blocking defects which improves the mobility of domains walls; leading to an increase in $\mathrm{Bm}$ and a decrease in Hc.

In zone III, Bm and Hc behave almost constant which could be controlled by the competence of both the order increase and the further recovery of the structure; as the annealing temperature increases.

Finally, in zone IV, above the B2 $\rightarrow$ bcc transformation at $973 \mathrm{~K}$ which allows a larger recovery of the structure due to the superdislocations vanish; $\mathrm{Bm}$ and $\mathrm{Hc}$ increases and decreases, respectively; as a consequence of an improvement in the mobility of the domains walls. Indeed, the decrease in the amount of quenched-in-defects and -dislocations, after the heating at temperatures over the B2 $\rightarrow$ bcc transformation, leads to an improvement of the magnetic quality, since the mobility of domains walls has increased because the less amount of obstacles interacting through a magnestotrictive phenomenon.

It should be highlighted that, as the magnetic loops are recorded at room temperature, the improvement of the magnetic quality after annealing temperatures over the $\mathrm{B} 2 \rightarrow$ bcc transformation, is controlled mainly by the recovery of defects and not by the B2 order degree, because the order state have reached already its maximum value. This is in agreement with several works, which not report a deterioration of the magnetic quality by the appearance of B2 order [20,21]. In contrast, the deterioration of magnetic quality was reported to appear with the development of $\mathrm{D}_{3}$ superstructure [20,21]. Therefore, in $\mathrm{Fe}-10$ at.\% $\mathrm{Si}$ alloys the magnetic quality is mainly controlled by the recovery of defects, being the B2 ordering a less important contribution.

Figure 9 shows the behaviour of $\mathrm{Bm}$ and $\mathrm{Hc}$ for the ternary Fe-6at.\% Al-9at.\% Si as a function of temperature, where three zones of different monotony can be chosen.

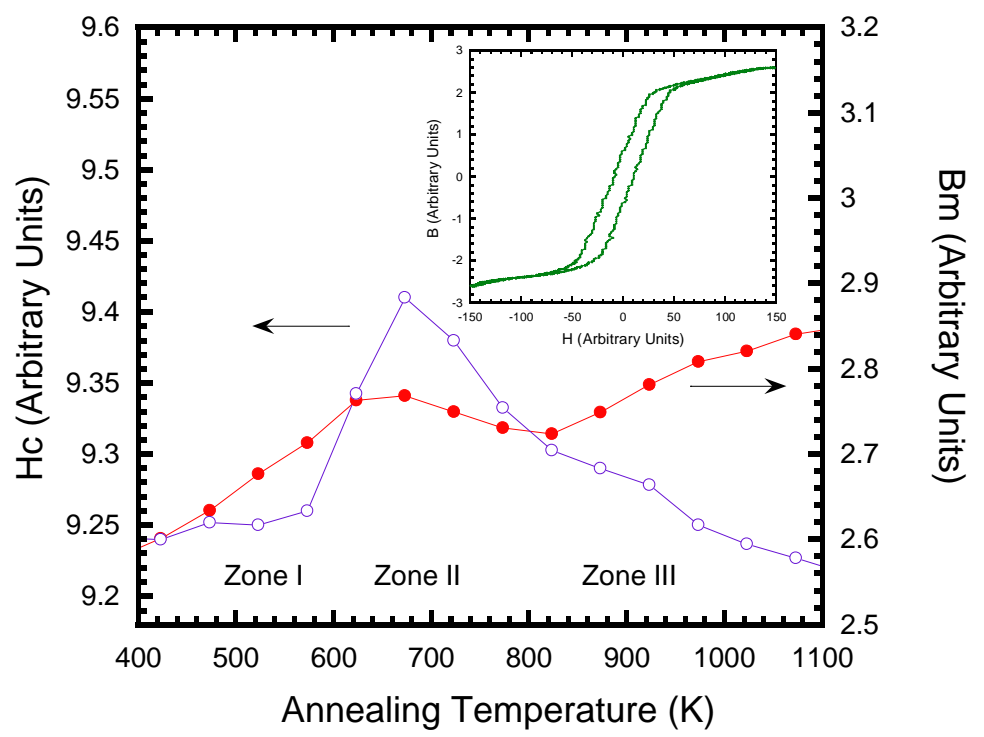

Figure 9: $\mathrm{Bm}$ and $\mathrm{Hc}$ as a function of annealing temperature for Fe-6at.\% Al-9at.\% Si. Being magnetic loops traced at room temperature. Inset shows a hysteresis loop.

The behaviour of $\mathrm{Bm}$ and $\mathrm{Hc}$ in zones I and II could be explained as a competition between the changes in the order degree and the enhancing of the vacancies mobility, revealed by the exothermal reaction with peak at $650 \mathrm{~K}$ in Figure 1. In fact, the increase in Bm and the almost constant Hc behaviour in zone I can be related to the enhanced mobility of vacancies related to their recovery, in agreement with the results for $\mathrm{Fe}-10 \mathrm{at} . \% \mathrm{Si}$. The subsequent decrease in $\mathrm{Bm}$ and increase in $\mathrm{Hc}$ in zone II could be related to the increase in the $\mathrm{DO}_{3}$ order contribution. Finally the increase in $\mathrm{Bm}$ and the decrease in $\mathrm{Hc}$, exhibited in zone III can be related to the recovery of quenched-in-defects, as a consequence of the $\mathrm{D}_{3} \rightarrow$ bcc transition, which is revealed by the increase in the mobility of defects viewed through the higher values of damping in the region of lower temperatures (see Figure 6). 
Figure 10 shows the behaviour of $\mathrm{Bm}$ and $\mathrm{Hc}$ for the ternary $\mathrm{Fe}-4 \mathrm{at} . \%$ Al-8at.\% Ge, where both behaviours are again not monotonous as a function of the annealing temperature, giving rise to three different stages. The decrease in Bm and increase of $\mathrm{Hc}$ in zone I (Figure 10) can be related to the decrease in the dislocations mobility by a pinning processes which through a magnetostrictive coupling diminishes the domain walls mobility. In zone II, where the improvement of the magnetic quality of the alloys starts, can be related to the increase in the mobility of point and linear defects, since the development of the GB is starting. Finally, the subsequent improvement of the magnetic quality in zone III can be related to an increase in the mobility of the domain walls due to a further recovery of the microstructure which gives rise to an enhanced mobility of defects, owing to the decrease in the amount of quenched-in defects.

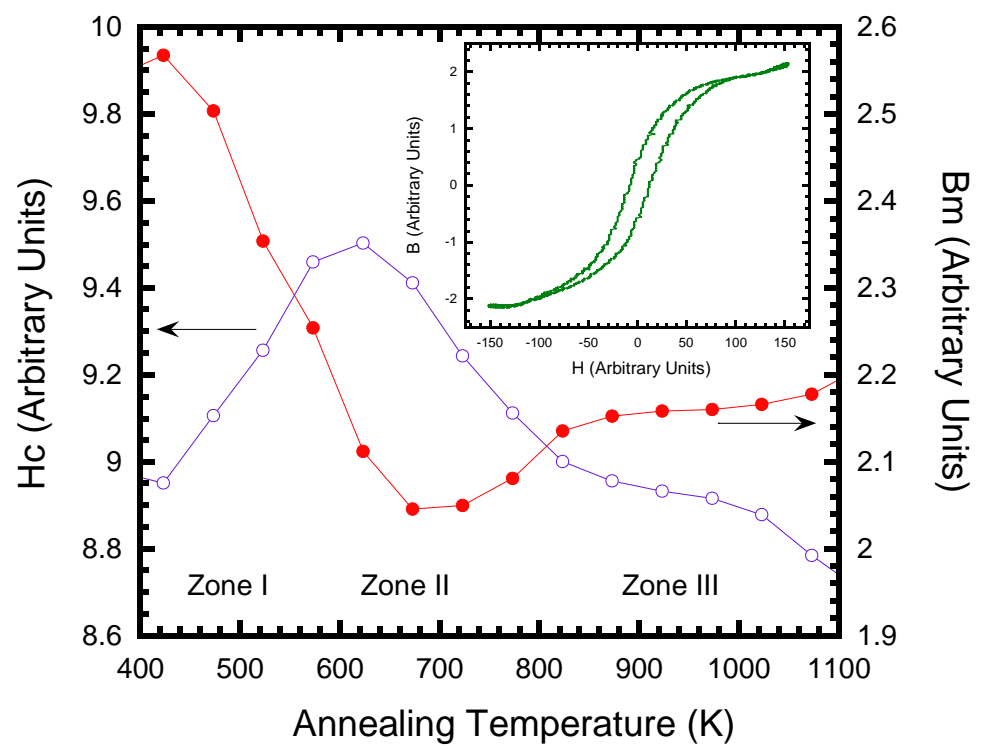

Figure 10: $\mathrm{Bm}$ and $\mathrm{Hc}$ as a function of annealing temperature for Fe-4at.\% Al-8at.\% Ge. Being magnetic loops traced at room temperature. Inset shows a hysteresis loop.

\section{CONCLUSIONS}

The influence of both the microstructural state and the type of order, and its changes, as a function of temperature on the magnetic properties in several Fe-based alloys has been determined. The microstructure has been characterized by means of differential thermal analysis, mechanical spectroscopy and neutron thermodiffraction studies, and the results were correlated to the magnetic properties.

The increase of order degree leads to a decrease in the mobility of the domain walls through a magnetostrictive effect, promoting a deleterious effect in the magnetic quality of the alloys.

It has been found that the B2 order has a less influence on the deterioration of the magnetic properties than $\mathrm{DO}_{3}$ order. In $\mathrm{Fe}-10 \mathrm{at} . \% \mathrm{Si}$, the magnetic properties improve always with an increase in the annealing temperature. In contrast, in Fe-6at.\% Al-9at.\% Si, it depends on the annealing temperature interval. There is a deterioration of the magnetic properties in the interval from 600 to $700 \mathrm{~K}$. For Fe-4at.\% Al-8at.\% Ge there appears a first zone where the magnetic properties does not improve due to the pinning of dislocations. At temperatures above $650 \mathrm{~K}$, an improvement in the magnetic behaviour develops due to the recovery and the annihilation of quenched-in-defects and -dislocations.

\section{ACKNOWLEDGEMENTS}

Authors wants to thanks to Institute Laue Langeving (ILL), Grenoble France for the allocated neutron beantime (exp. CRG-1121) and NKK Corp and Prof I. S. Golovin for supplying Iron Silicon and ternary alloys respectively. This work was partially supported by CONICET, PIP 0179, PID-UNR; ING 450 and 453 and the Cooperation agreement between the UPNA and UNR Res. 3247/2015.

\section{BIBLIOGRAPHY}

[1] FIORILLO, F., Measurement and characterization of magnetic materials, Amsterdam, Elsevier, 2004. 
[2] BOZORTH, R.M., Ferromagnetism, Princeton, D. Van Nostrand Company Inc, 1964.

[3] CULLITY, B.D., Introduction to magnetic materials, Reading, Addison-Wesley, 1972.

[4] FITZGERALD, A.E., KINGSLEY, C., UMANS, S., Electric machinery, New York, McGraw-Hill Book Company, 1983.

[5] LAMBRI, O.A., "A review on the problem of measuring non-linear damping and the obtainment of intrinsic damping", in: Martinez-Mardones J., Walgraef D., Worner C.H. (Eds.), Materials Instabilities, World Scientific, pp. 249-280, 2000.

[6] LAMBRI, O.A., PEREZ-LANDAZABAL, J.I., CANO, J.A., RECARTE, V., "Mechanical spectroscopy in commercial Fe-6 wt.\% Si alloys between 400 and 1000 K", Mater. Sci. Eng. A. V. 370 pp. 459-463, March 2004.

[7] FRANK, W., SEEGER, A., WELLER, M., "Interpretation of positron annihilation experiments on electron-irradiated a-iron in terms of self-interstitial migration in stage III.", in: Robinson M.T., Young F.W. Jr. (Eds.), Fundamentals Aspects of Radiation Damage in Metals, US ERDA CONF-751006, Oak Ridge, 1976.

[8] ELDRUP, M., "Application of the positron annihilation technique in studies of defects in solids", in: Chadwick, A.V., Terenzi, M., Defects in Solids, New York, NATO ASI Series, 1985.

[9] WELLER, M., DIEHL, J., TRIFTSHÄUSER, W., "Investigations of neutron irradiated iron by positron annihilation and correlated internal friction measurements", Solid State Commun., V. 17, pp. 1223-1226, Nov. 1975.

[10] HUMPHREYS, F.J., HATHERLY, M., Recrystallization and related annealing phenomena, Netherlands, Pergamon, 2002.

[11] LAMBRI, O.A., BULEJES, E.D., GORRIA, P., TINIVELLA, R.J., "Mechanical spectroscopy study in commercial grain oriented silicon steel", J. Mater. Sci., V.35, pp. 79-85, Jan. 2000.

[12] LAMBRI, O.A., PEREZ-LANDAZABAL, J.I., CUELLO, G.J., CANO, J.A., RECARTE, V., SIEMERS, C., GOLOVIN, I.S., "Mechanical spectroscopy in Fe-Al-Si alloys at elevated temperatures", $J$. Alloys Compd., V. 468, pp. 96-102, Dec. 2009.

[13] MIYAZAKI, T., KOZAKAI, T., TSUZUKI, T., "Phase decompositions of Fe-Si-Al ordered alloys", J. Mater. Sci., V. 21, pp. 2557-2564, July 1986.

[14] PAVlOVA, T.S., GOLOVIN, I.S., SINNING, H.R., GOLOVIN, S.A., SIEMERS C., "Internal friction in Fe-Al-Si alloys at elevated temperatures", Intermetallics, V. 14, pp. 1238-1244, Oct. 2006.

[15] LAMBRI, O.A., PÉREZ-LANDAZÁBAL, J.I., GARGICEVICH, D., RECARTE, V., BONIFACICH, F.G., CUELLO, G.J., SÁNCHEZ-ALARCOS, V., "Order evolution in Iron-based alloys viewed through amplitude dependent damping studies", Mater. Trans., V. 56, pp. 182-186, Jan 2015.

[16] MOLINAS, B.J., POVOLO, F., "Present state of the controversy about grain boundary relaxation", Nuovo Cim., V. 14, pp. 287-332, March 1992.

[17] LAMBRI, O.A., PÉREZ-LANDAZÁBAL, J.I., CUELLO, G.J., GARGICEVICH, D., RECARTE, V., BONIFACICH, F.G., GIORDANO, E.D., SANCHES-ALARCOS, V., "Relation between order degree, damping behaviour and magnetic response in Fe-Si and Fe-Al-Si alloys", Neutron News, V. 25, pp. 28-31, Oct. 2014.

[18] GARGICEVICH, D., LAMBRI, O.A., PÉREZ-LANDAZÁBAL, J.I., RECARTE, V., BONIFACICH, F.G., CUELLO, G.J., SÁNCHEZ-ALARCOS, V., "Mobility of dislocations and grain boundaries controlled by the order degree in iron-based alloys", J. Phys. Conf. Ser., V. 663, pp. 12013, Dec. 2015.

[19] CAHN, R.W., HAASEN, P., Physical Metalurgy 3rd edition, Amsterdam,North Holland Physics Publishing, 1983.

[20] VIALA, B., DEGAUQUE, J., BARICCO, M., FERRARA, E., PASQUALE, M., FIORILLO, F., "Magnetic and mechanical properties of rapidly solidified Fe-Si $6.5 \mathrm{wt} \%$ alloys and their interpretation", $J$. Magn. Magn. Mater., V. 160, pp. 315-317, 1996.

[21] VIALA B., DEGAUQUE, J., FAGOT, M., BARICCO, M., FERRARA, E., FIORILlO, F., "Study of the brittle behaviour of annealed Fe-6.5 wt\%Si ribbons produced by planar flow casting", Mater. Sci. Eng. A., V. 212, pp. 62-68, 1996. 